\title{
Visual Encounters with the Past: Teaching Visual Literacy to Enhance Historical and Cultural Understanding
}

\author{
Peggy Keeran \\ University of Denver, USA \\ Katherine Crowe \\ University of Denver, USA \\ Jennifer Bowers \\ University of Denver, USA
}

\begin{abstract}
At the University of Denver, the reference librarians and special collections curator have developed strategies to incorporate visual literacy into instructional sessions across multiple disciplines. In this chapter, we will discuss our collaborations with faculty in anthropology and in history to help students interpret tangible and digital archival visual information that will inform their understanding of historical contexts and meet learning outcomes in two classes: "Native American Resistance in the Digital Age" and "World War I." Whenever we partner with faculty to include visual literacy in non-arts courses, we start with course outcomes and work with the faculty to determine how the incorporation of visual literacy can help reach those goals. Our process is iterative, practice based, flexible, and ever evolving. This chapter will provide practical strategies that educators can use to implement this type of collaboration at their own institutions.
\end{abstract}

Keywords: critical visual literacy, information literacy, librarian/curator/faculty collaborations, primary source research

\section{Partnering on Visual Literacy and Information Literacy}

Visual literacy is an important aspect of information literacy that is not often included into non-arts-based library instruction, despite the multitude of visual materials that can be used in partnership with text-based course materials to deepen and enrich the instructional experience. Many non-arts librarians and archivists do not have backgrounds in the arts and may be hesitant to bring visual materials and visual literacy-based exercises to their coursework, but as Matusiak et al. (2019) have shown in their study of undergraduate and graduate students, not incorporating visual literacy into coursework is a lost opportunity that leaves a gap in the students' knowledge base.

In this chapter, we cover how we have developed ongoing partnerships between archivists, subject librarians, and teaching faculty in non-arts disciplines to co-create activities using visual materials based on course outcomes and goals to mitigate some of the knowledge gaps that Matusiak et al. (2019) and others in visual literacy studies have noted. Collaborations between library faculty and teaching faculty highlight potential areas of mutual benefit and strengthen existing relationships. Working with the archives can allow for the inclusion of visual primary sources into in-classroom library instructional activities, which can spark student wonder and excitement in ways that may not happen if instruction focuses only on visual materials in library databases. We have discovered that, even if the physical collections are limited, incorporating tangible materials into activities can make a real difference in student engagement. At the same time, utilizing materials in databases can open up possibilities to explore archival and other visual materials from all over the world, expanding the opportunities for deep dives into discipline-specific areas.

Above all, collaboration is an ongoing and iterative process and it is necessarily sometimes slow and organic in nature. We have worked with teaching faculty and each other over time to seek opportunities for mutual benefit, from partnering with faculty when they are developing new courses, to applying jointly for library grants to redevelop and refine aspects of their courses with visual information literacy in mind. We are committed to growing and developing this process, as it will always be evolving. 


\begin{abstract}
Visual Literacy
The 2011 ACRL Visual Literacy Competency Standards for Higher Education defines visual literacy as "a set of abilities that enables an individual to effectively find, interpret, evaluate, use, and create images and visual media," including crucial skills such as understanding and analyzing context and culture. In 2016, ACRL formed a Visual Literacy Task Force to update the standards to align with their Framework for Information Literacy for Higher Education. At the International Visual Literacy Association's virtual conference in 2020, Thompson et al. (2020) presented preliminary findings identified by the ACRL Visual Literacy Task Force about issues of increasing importance to visual literacy instructors, based upon surveys and interviews. Several of these issues reflect our own visual literacy teaching experiences, such as: moving away from skills-based standards towards dispositions and habits of practice; incorporating critical visual literacy into our instruction, which, in addition to contextualizing images per visual literacy, investigates power relations; and prompting students to practice "slow looking," or slowing down to examine what they are seeing. The task force members also identified challenges and opportunities in the visual literacy interviews which resonate with us, such as the role of librarians and curators in visual literacy instruction and the collaborations between librarians and discipline faculty to introduce visual literacy to students (in our case, non-arts students) in order to help them to both meet the goals of the course and to develop life-long learning skills that are crucial in today's visually-rich online culture (Thompson et al., 2020). For non-arts librarians interested in the idea of slow looking as a visual literacy skill, the Toledo Museum of Art has a helpful website on the steps in the process that first entail looking, observing, and seeing, and then describing, analyzing, and interpreting (Visual literacy: The art of seeing art).
\end{abstract}

Three themes in the recent literature inform our approaches to visual literacy instruction. The first theme involves the prevalence of images available to students and the mistaken assumption that students are able to critically evaluate and contextualize meaning, which underscores the crucial role of visual literacy in today's academic environment and in life-long learning. In their study, Matusiak et al. (2019) determined that undergraduate and graduate students across non-arts disciplines show that "being surrounded by visual media does not necessarily mean that students know how to find appropriate images, understand their meaning and cultural context, or integrate them into academic work" (p. 124).

The second theme concerns the uncertain role librarians should play in engaging students with visual objects. By surveying academic librarians, Schwartz (2018) found that many don't know about the visual literacy standards and don't address visual literacy in their instruction, while others believe it isn't the role of the librarian to be involved in visual literacy at all. Schwartz described visual literacy instruction that centered on creating visual materials rather than critically examining them, and it is understandable to us that many academic librarians would feel those skills were beyond their abilities and job descriptions. Our interest is in the analysis of visual primary sources rather than in image creation, although we do collaborate with faculty who have their students create knowledge through exhibits. Even as the task force is aligning the standards with the framework, Meeks (2017) examined ways in which the standards and the ACRL Framework for Information Literacy in Higher Education could be used to situate visual literacy within information literacy. Although she works primarily with those in arts and design, she advocates for visual arts librarians to take the lead and "help guide the development of the habits of mind needed to understand and thoroughly teach visual literacy across the library profession" (Meeks, 2017, p. 194). Early on, after the standards were developed, Beatty (2013) provided examples of visual literacy instruction that addressed each of the standards, and that would help alleviate librarian anxiety about incorporating visual literacy into instruction. In Visual Literacy for Libraries: A Practical, Standards-Based Guide, Brown, Bussert, Hattwig, and Medaille (2016) offered examples of instruction strategies and activities to help academic librarians apply, teach, and promote visual literacy.

The third theme is the emergence of critical visual literacy into instruction by academic librarians willing to take the plunge into this still somewhat unchartered area. Instruction based upon the standards is helpful, but as Grimm and Meeks (2017) pointed out, "the focus on specific outcomes, presented as bite-sized pieces that can be taught apart from one another, obscures the potential intersections and synthesis of some of these larger ideas" (p. 177). This includes the philosophical shifts in library instruction brought about by the Framework, and the growing interest in critical information literacy that inform their instruction. Grimm and Meeks centered social justice in visual literacy instruction, employing the theories and practices of critical librarianship and feminist pedagogy to ensure students go beyond finding, analyzing, and using 
images, to also engage with power structures and social issues. Beatty and Hernandez (2019) collaborated on applying socially responsible pedagogy to combine critical information literacy and visual literacy in a for-credit information literacy class, using activist art and social justice imagery. Although Grimm, Meeks, Beatty, and Hernandez all discussed arts and design students, their pedagogical approaches inform librarians working with non-arts students in different disciplines, much as Meeks advocated.

In our collaborations with faculty, we guide non-visual arts students to begin to think critically about the cultural and historical contexts of images and visual materials they discover in physical and digital archives, especially those that saturate our popular culture (e.g., the Curtis prints discussed below). Thus far, our visual literacy instruction has been introductory, since the faculty, librarians, and students are not necessarily in disciplines that normally engage with visual materials. We don't expect the students to emerge from our instruction sessions as experts, but as individuals stretching their skill sets to become more comfortable analyzing and thinking critically about visual materials they find.

\section{Visual Literacy and Historical and Cultural Context}

\section{Native American Resistance in the Digital Age}

Both the archivist and social sciences librarian had been collaborating with Dr. Esteban Gómez on instruction for a few years before the opportunity arose to partner on his anthropology course, "Native American Resistance in the Digital Age." The course attracted primarily graduate students from anthropology, education, and religious studies. Dr. Gómez's goals for the course were: have students evaluate resistance from a historical standpoint, ensure students understand how Indigenous knowledge systems contest Western conceptions of authority through art and digital media, and have students explore the voice and agency of Indigenous people in different fields.

In order to effectively tailor the visual literacy activities, we met with Dr. Gómez to discuss the course learning outcomes and to identify possible archival collections that would support those goals. Dr. Gómez had outlined specific learning outcomes in his syllabus that could be enhanced through visual explorations and we decided to focus on two in particular. The first was for students to examine Native American resistance through an interdisciplinary lens. Although this was an anthropology class, the students would be exploring resistance from a wide range of disciplinary perspectives. In fact, they would apply a postcolonial approach "to understand how Indigenous filmmakers, curators, scientists, healers, artists, and scholars use Indigenous knowledge systems to contest Western conceptions of authority" (E. Gómez, syllabus, spring quarter 2019, p. 1). Consequently, the students would be considering Indigenous resistance, creativity, and cultural heritage from anthropology, art, photography, museum studies, communication and media, literature, film, medicine, and science fields. Dr. Gómez also wanted the students to examine Native American resistance over time, from the early encounters of first European contact and during the American colonial period, through westward expansion and into the present, so that studying these events from historical perspectives was also important.

This first learning outcome was closely aligned with the second; Dr. Gómez wanted students to engage with Indigenous epistemologies for a better understanding of the ways in which Native Americans and other Indigenous peoples have experienced the systematic marginalization of their voices and agency both in and through the media and governmental policy. We also approached this learning outcome from historical perspectives, so that students could analyze the range of Native American visual representation by settler colonialists, and critically examine how these images contributed to the foundation of enduring stereotypes.

Dr. Gómez has been an enthusiastic supporter of library instruction and we have partnered with him previously on several of his upper and lower division undergraduate and graduate level classes, including a Visual Ethnography class that served as a prototype for the visual analysis activities described in this chapter. Building on existing relationships is central to gaining faculty engagement when proposing new collaborations and types of literacies. Dr. Gómez was awarded the Joseph I. Moreland Information Literacy Grant for the "Native American Resistance in the Digital Age" class. This internal grant is designed to encourage faculty to partner with subject librarians and/or the curator of special collections and archives to integrate information literacy into their classes, especially those classes that count towards major credits. As stated in his grant application (and based on conversations with the social sciences librarian and curator 
of special collections), Dr. Gómez wanted to focus on inclusive authorities, so that students would learn how to search for secondary and primary sources written and created by Indigenous authors. To support this learning outcome, we designed our visual literacy activities around the "Authority is Constructed and Contextual" ACRL Information Literacy for Higher Education frame. In addition, a class research guide provided students with strategies and resources for identifying Indigenous-created scholarship, creative works, archival materials, and perspectives.

Together, we planned for three library sessions with the students that would feature our archival and special collections. Since the course investigated Indigenous resistance from the colonial era onwards, we decided to highlight our eighteenth- and nineteenth-century captivity narratives, and also use the Edward S. Curtis portfolio of photogravure prints, The North American Indian, and reproductions of nineteenth-century artist George Catlin's paintings of Native Americans as a way for students to analyze Western European representations of Native peoples. The students critiqued foundational stereotypes and tropes, such as the "land as an empty wilderness," the image of the "noble or barbarian savage," and the portrayal of Native Americans as a "vanishing race." To contrast these stereotypes, we drew upon our "Native American, First Nations, and Indigenous Graphic Novels" collection to examine Indigenous self-representation, agency, storytelling, resilience, and resistance to settler colonial narratives and visual representation. All three sessions employed visual literacy strategies, although the students also reviewed the captivity narrative and graphic novel texts and captions. Class discussions during each session addressed historical context and theoretical concepts, with particular attention to how visual and textual representation contributes to, or counters, dominant cultural narratives and colonial legacies about Native peoples.

\section{Native American Captivity Narratives}

The first session with the Native American resistance class focused on our small but growing collection of Native American captivity narratives. This genre in the United States developed over time with American westward expansion and often featured an Anglo-American woman taken captive by Indigenous peoples (Johnson, 2016). Though captivity narratives aren't unique to either the United States or to this period of American history, this sub-genre provides significant insight into settler colonists' anxieties about Native peoples in areas of white settlement.

Before the session, students read selections from Buried in Shades of Night (Stratton, 2013), which analyzes Mary Rowlandson's influential captivity narrative that took place during what is sometimes called King Phillip's War in the mid-1670s. This story was told and re-told in subsequent editions and reprintings that were, Stratton argues, published at times that were intended to heighten white settler suspicions about Native Americans as the enemy, such as the years leading up to the Revolutionary War (p. 20). Students worked in small groups to analyze several pre-selected captivity narratives in our collection with illustrations, with each group sharing their analysis as the class concluded.

We adapted a visual analysis exercise from Visual Literacy for Libraries (2016), which asked students to: look (at the image composition, people, and setting), read (determine the purpose of textual information that accompanies the image), examine (see if the text changes the analysis of the image), and then describe and interpret (why might the image have been created, what is the image's intended audience, does it fit with or disrupt what you know? How does or might this form of visual representation contribute to enduring stereotypes about Native peoples?).

Students then chose a captivity narrative from HathiTrust Digital Library, and selected an excerpt to read and analyze for individual essays and group presentations that addressed the question: "What are we to understand about this captivity narrative's representation of Native culture(s), and its method of composition? What tropes and stereotypes are present?" Multiple students commented that they needed the context and grounding from the reading prior to the session, which dealt specifically with the title page illustration from the 1773 edition of Rowlandson's story (see Figure 1), so that they had the tools to effectively analyze the images present in the captivity narratives for their assignments.

\section{Figure 1}


Rowlandson, M. W. (1773). Title page illustration. A narrative of the captivity, sufferings, and removes of Mrs. Mary Rowlandson. John Boyle's Printing-Office. Courtesy of University of Denver Special Collections and Archives.

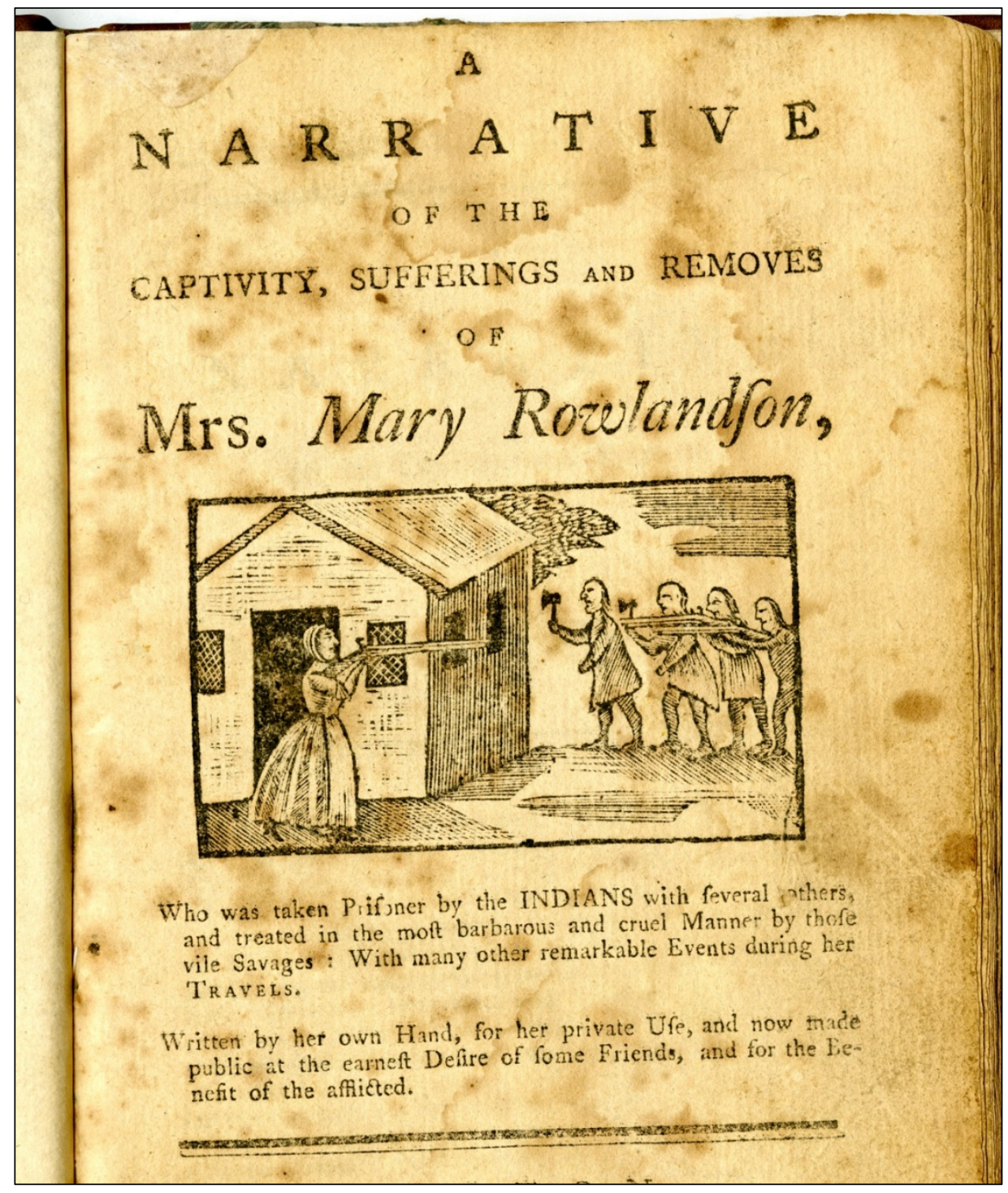

\section{Edward S. Curtis's The North American Indian}

Prior to the next session, the students watched the documentary, Coming to Light (Makepeace, 2000), and read an article titled "The Photograph as an Intersection of Gazes: The Example of National Geographic" (1991). The goal of this session was to explore the significance of the "gaze" in the representation of Native peoples by white settlers - in this case, the painter George Catlin and the photographer Edward Curtis. The images used were all of the Hopi people and the librarians and faculty intentionally selected a variety of genres, including portraits, group photographs, landscapes, and architecture. Students were asked to carefully examine the visual contents of the photographs and their composition. The goal was to pay close attention to visual details, rather than provide an interpretation of the photographs. The students then did the same with Catlin's paintings, which were in color art monographs. Students followed the session by selecting one photograph or painting, according to the professor's prompt, for a reflective essay that responded to the article on the Western gaze.

Curtis sometimes orchestrated or altered the photogravures during the printmaking process, which provide 
teaching opportunities. Coming to Light incorporates interviews with descendants of people who were photographed by Curtis, several of whom recalled oral histories from their ancestors about having been asked to dress a certain way (or even being given clothing that was not theirs). It also covers the most (in)famous example of a print that Curtis altered, titled "In a Piegan Lodge" in the full limited edition set of The North American Indian. In the photogravure print, Yellow Kidney and his father, Little Plume, pose in a lodge with a clock in between them (see Figure 2); the clock is visible in the photographic print, held by the Library of Congress, made directly from the glass plate negative but it does not appear in the photogravure print that is part of The North American Indian limited edition set (see Figure 3). We have used this photogravure print juxtaposed with the digitally available photographic print several times, and students often do not notice this alteration or other changes or discrepancies unless they are prompted to do so. This is another example of how "slow looking" (Thompson et al., 2020; Toledo Museum of Art) can be a great addition to in-class activities; otherwise students (especially in non-arts classes) are prone to speed through the visual analysis and miss important details.

\section{Figure 2}

Curtis, E. S. (1910 March 11) In a Piegan Lodge. Curtis (E. S.) Collection (Curtis no. 3122-10). Library of Congress, Washington, D.C. https://www.loc.gov/item/2003652798/

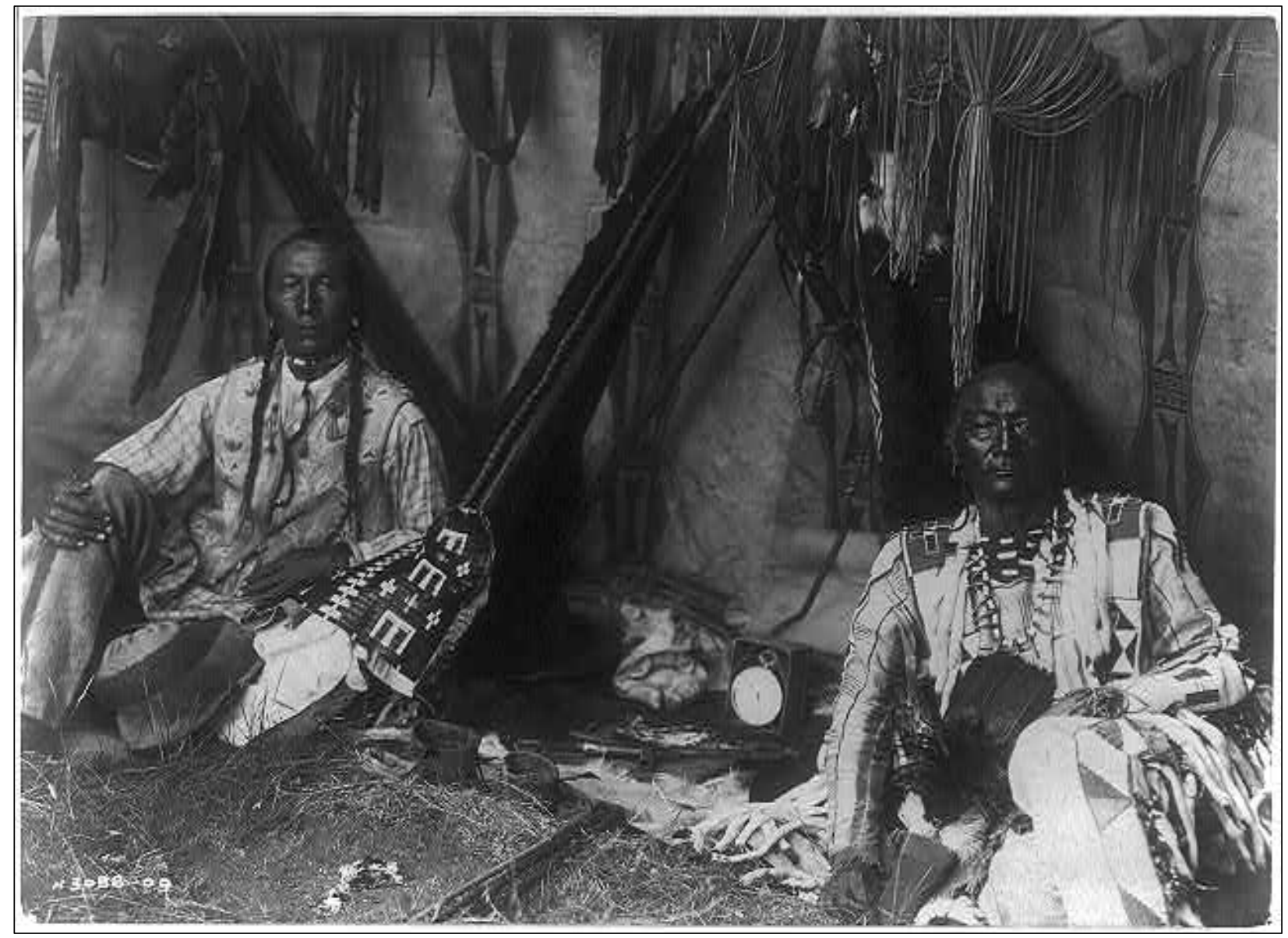

Figure 3 
Curtis, E. S. (1906). In a Piegan Lodge (portfolio 6, no. 188). The North American Indian. E.S. Curtis. Digital Edition of the North American Indian, http://curtis.library.northwestern.edul

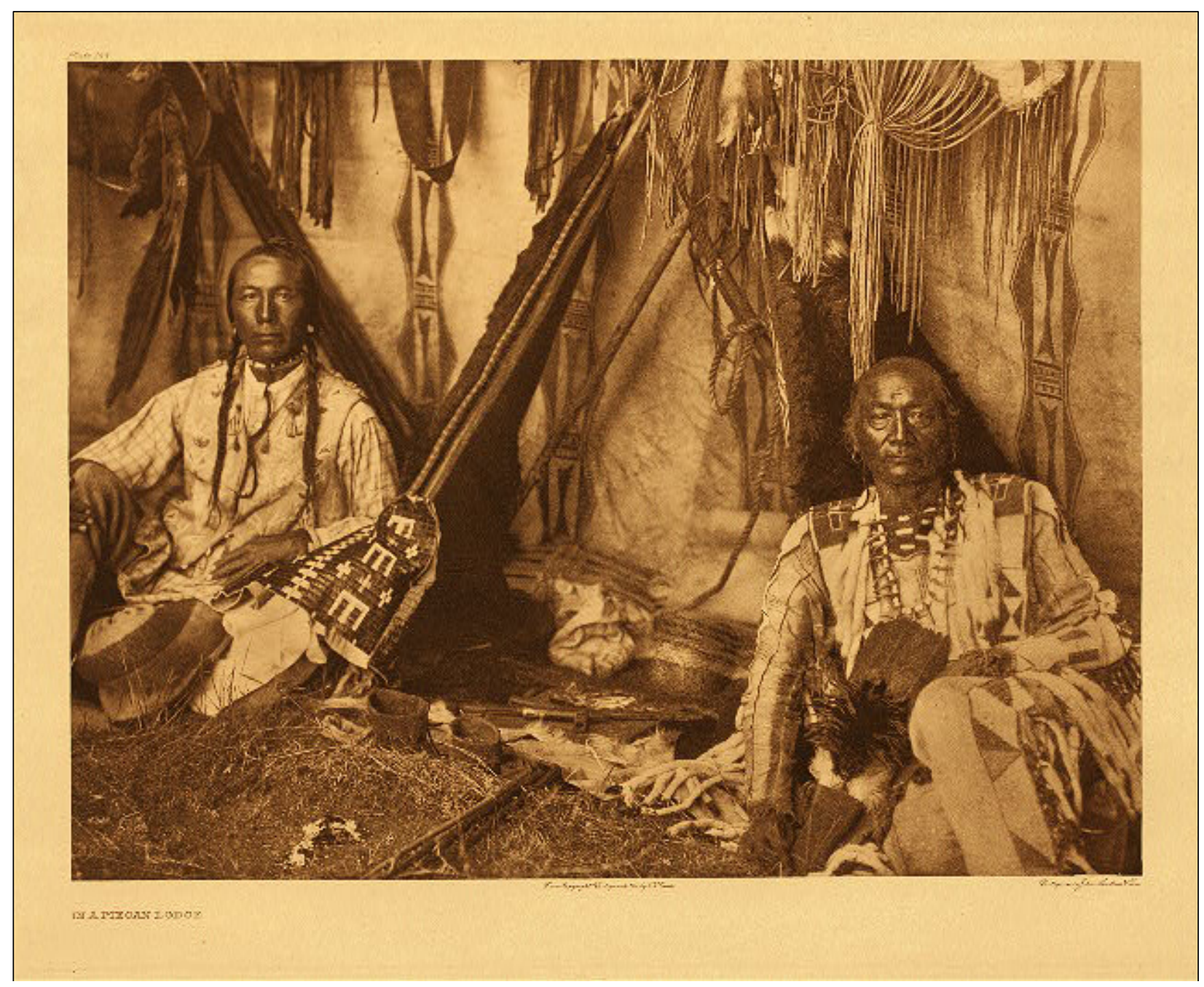

During the session, the students raised ethical questions that we need to address, namely: consent, community-based Indigenous intellectual property, and cultural patrimony. We discussed the implications of not having a memorandum of understanding with the Hopi nation to study these images. We will be convening a small group of faculty partners, some of whom are Indigenous, to develop guidelines for classroom use of these images going forward. This situation raises an important point, namely, that instructors should always consider the ethics of including images of colonized or otherwise vulnerable people or communities, particularly if the instructors are not members of the communities.

\section{Graphic Novels}

The University of Denver was founded in 1864 by John Evans, acting Territorial Governor in Colorado, the same year that the notorious Sand Creek Massacre occurred on November 29, in which hundreds of peacefully assembled Arapaho and Cheyenne were attacked and murdered by government troops. In 2014, (the 150th anniversary of both events), the University published the Report of the John Evans Study Committee, which found Evans culpable for the massacre. The report concluded, "John Evans's pattern of neglect of his treaty-negotiating duties, his leadership failures, and his reckless decision-making in 1864 combine to clearly demonstrate a significant level of culpability for the Sand Creek Massacre..." (ClemmerSmith et al., 2014, p. iii). 
In light of our university's terrible legacy and troubled past history with the Arapaho and Cheyenne nations, and also to diversify and increase representation of Native American-authored works in our holdings, we have been building a collection of Native American and Indigenous graphic novels (to complement our collections of other Native American works) that was the focus of our final visual analysis session. The collection currently comprises more than thirty titles by creators such as Gord Hill, David Alexander Robertson, Arigon Starr, Elizabeth LaPensée, Katherina Vermette, Richard Van Camp, Michael Nicoll Yahgulanaas, Jay Odjick, and Patti LaBoucane-Benson, among others. Canada has a very robust Indigenous graphic novels community and, currently, most of the titles in our collection are by First Nations Canadian authors and illustrators. We worked together with Red Planet Books/Native Realities Press in Albuquerque, New Mexico, and also consulted recommended titles from Debbie Reese's, "Best Graphic Novels by Native Writers," American Indians in Children's Literature blog post and the Highwater Press title list to form the collection initially. We plan to attend the Indigenous Comic Con to identify additional authors and titles. Our hope is to use this growing collection for teaching with many different academic disciplines, as the novels lend themselves to analysis from arts, humanities, and social sciences perspectives. Although seen as a popular and accessible genre, graphic novels can address serious and complex topics in meaningful ways (for example, Art Spiegelman's classic graphic novel about the Holocaust, Maus: $A$ Survivor's Tale). They are also increasingly a medium through which underrepresented or minoritized communities can speak about their experiences and reach a wider audience. As a testament to the transformative power and impact that graphic novels can play in Native American agency and representation, Dr. Niigaanwewidam James Sinclair (2020, January 30), writes, "They are a culmination of the control that Indigenous people have over their own images and what is said about them... It's the most revolutionary text there is" (History, About the Mazinbiige Indigenous Graphic Novels Collection section, para. 8).

In order to prepare students for the graphic novels visual analysis session, the students read the article, "' $A$ Necessary Antidote': Graphic Novels, Comics, and Indigenous Writings," by Henzi (2016), and they were given an introduction to analyzing comics by their classmate and anthropology graduate student, Melissa Kocelko, whose master's thesis research concerns Native American comics. Echoing Dr. Sinclair's statement, Henzi's (2016) article also emphasizes that graphic novels, like Gord Hill's The 500 Years of Resistance Comic Book (see Figure 4), "underlines the importance of this different medium, and of the visual, as necessary tools towards raising awareness of colonial history and towards raising awareness of long-lasting resistance efforts to ensure the continuity and transmission of traditions and storytelling for future generations" (p.25).

During the session, students worked in small groups to select and analyze a compelling graphic novel from our collection. Dr. Gómez created the assignment, which was intended to enable students to explore the structure of graphic novels by paying attention to the format, visual content, text, and narrative. Students began by examining the format, looking specifically at the layout, panel arrangement, frames, and gutters, and by noting any images that extended to or beyond the edge of the page in a technique referred to as bleed. Next, the students selected a sample of panels and bleeds to answer questions about visual content. During this part of the activity, the students identified where objects were placed, such as the foreground, midground, or background, and to note whether specific objects or characters occupied a particular space. The students also identified individual colors or objects that drew the eye more than others, as an indication of graphic weight. They looked closely at the faces of the characters and paid attention to the kinds of expressions most often associated with primary and supporting characters. Finally, they examined shading and color for particular characters, objects, and panels. The third part of the activity was focused on the narrative components of selected panels and bleeds, during which the students answered questions about how captions in the story were employed for scene setting and descriptions. The students were asked to look at the use of speech balloons for both internal dialogue and external dialogue between characters, and also their reinforcement of character development. The last part of the activity was centered on the graphic novel's narrative; students were charged to identify the major themes of the story, who the ideal or intended audience might be for these works, and to assess how all the different elements of format, visual content, and text support the overall narrative structure. Finally, and central to the learning outcomes, the students were asked to critique the methods employed in these stories responding to and countering settler colonial narrative themes and representations and, in turn, the means by which the novels empower Native agency, perspectives, and resilience. Some of the graphic novels did this in more overt or subtle ways. 


\section{Figure 4}

Hill, G. (2010). Cover. 500 years of resistance comic book. Arsenal Pulp Press. Reproduced with permission of Arsenal Pulp Press.

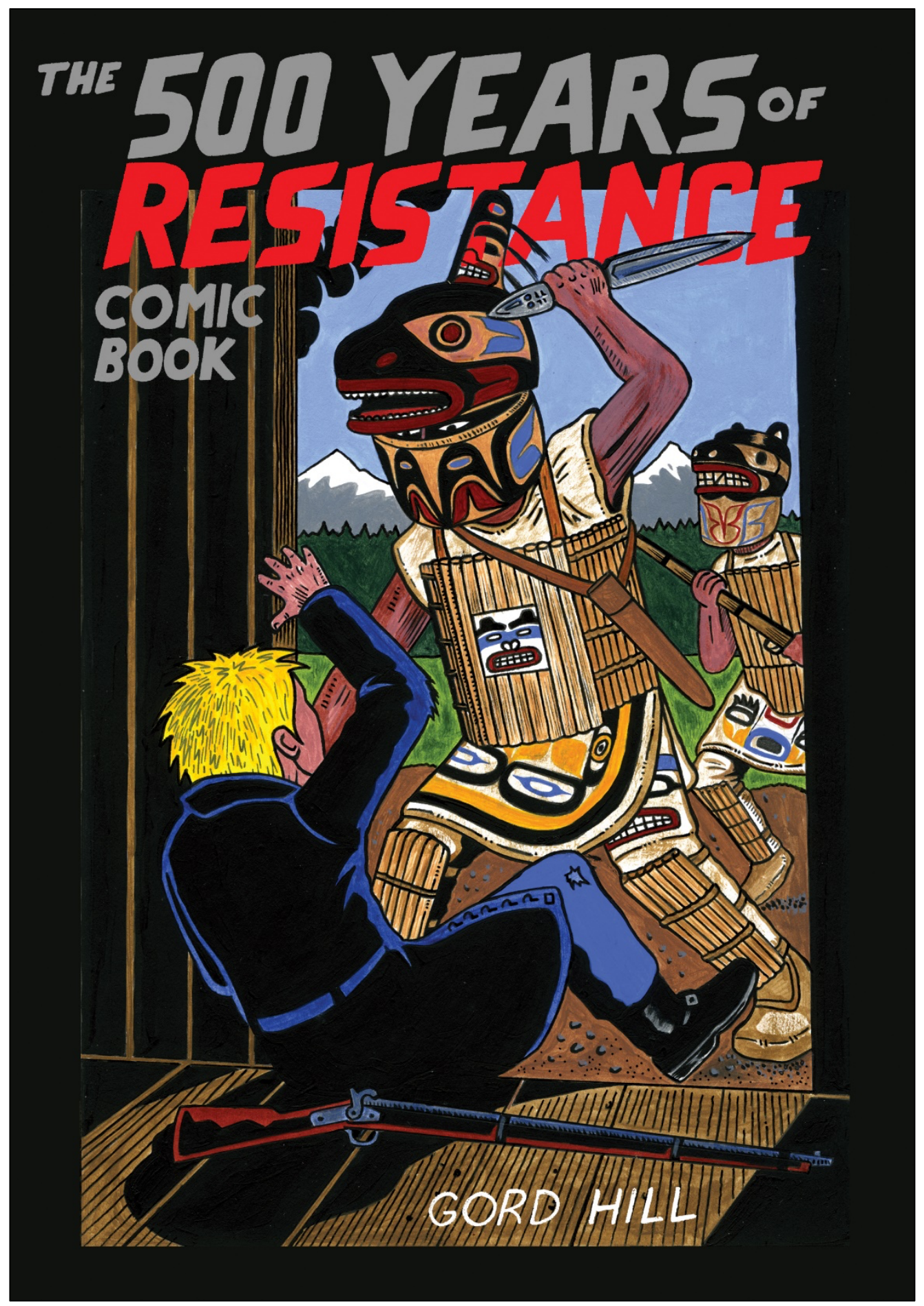

We plan to adapt these visual literacy workshops focused on Native American foundational stereotypes and counter narratives to an online format for Dr. Ramona Beltrán's graduate social work class, "Historical Trauma and Healing." In addition to determining the best ways for students to work online with the captivity 
narratives, Curtis prints, and graphic novels (due to the COVID-19 pandemic), we are also considering how to make the activities meaningful for a visually-impaired student, or for those students who prefer an audio format of the graphic novels. Consequently, we are exploring the possibility of using the audio comic, Unseen, created by Chad Allen, a self-identified blind artist and featuring a blind protagonist, the audio version of Neil Gaiman's graphic novel, Sandman, or Mira Jacob's book, Good Talk: A Memoir in Conversations. The students will most likely also have an online presentation and comic-making workshop with NAGPRA Comics series co-producer, Jen Shannon, a museum curator and associate professor of cultural anthropology. In ways similar to our graphic novels collection, NAGPRA Comics, "a communitybased, collaboratively produced comic series that tells true stories about repatriation from tribal perspectives" (What Is NAGPRA Comics? section, 2019) aims to redress historical injustices by centering Indigenous narratives.

\section{World War I}

Since the fall quarter of 2015, the arts and humanities librarian and the archivist have been collaborating with Dr. Carol Helstosky who teaches the "World War I" class. We focus on tangible and digital primary source research in the course, which allows for students to interrogate the narratives they encountered in their secondary readings by locating and interpreting contemporaneous primary sources. Most undergraduates in this lower-level course are non-majors, with varied knowledge about the war and its implications for future wars and society. Through this approach, the professor ensures "students learn what it is that historians 'do' when they approach research and analysis," gaining skills to interpret secondary sources through their own analysis (C. Helstosky, syllabus, spring quarter 2020, p. 1) We collaborate to help students develop into confident, critical thinkers, centering them in the research process and empowering them to question and research the historical record.

Every year when we teach this class together, we have the students immerse themselves in the Adam Matthew First World War Portal database on the first day of class. After a short instruction on navigating the database, students were directed to find two sources that interested them, and, in a worksheet, describe those objects and then list three questions each of the objects raised for them. In a second session, students would then explore a variety of digital primary sources in other commercial and freely-available digital collections, from trench journals to diaries to war resisters' documents. We found that the students' interests varied widely, but we were struck by the fact that many students would choose visual objects in that initial class. At the end of the academic quarter, students were again asked to explore the digital primary source databases, and a few would choose visual materials. However, almost none of the students included visual sources in their final projects. Although we didn't ask the students explicitly why, we found some possible answers in the scholarly literature. In their analysis of scholarly history journals from 2000 through 2009, Harris and Hepburn (2013) found that, for various reasons, research involving images by historians did not increase, despite the growth in availability of digital images. Without scholarly models, perhaps undergraduate students do not feel confident about their abilities to use visual materials in their projects. In her study on archival photographs in research being conducted by historians, Chassanoff (2018) had to expand her search beyond history faculty because "it was difficult initially to locate individual historians working in academic history departments who were using digitized photographs to make historical arguments" (p. 148). This lack of scholarly models for incorporating visual materials into academic publications contributed to our decision to demonstrate for students how to interrogate a visual image.

We assessed the questions raised by the students in those first worksheets, and we found that the questions the students asked about the objects fell largely within four categories: effectiveness, purpose, iconography/representation/stereotype, and misunderstanding/mislabeling (Keeran et al., 2019). Because a great deal of information was disseminated to the public via images during World War I, we brainstormed how to have students analyze and contextualize this vital part of visual culture, and we began with propaganda posters, which combined text and images. We decided to address this important aspect of the war, and restructured part of the library workshop to ensure all students developed introductory skills related to the visual culture of World War I.

James (2009) points to the wide distribution of war posters in combatant countries that were created to persuade the home front of the importance of supporting the effort. Advertising posters were already a wellestablished means of reaching consumers, and governments used this avenue of communication to unite 
the population through messages that stressed national characteristics needing preservation from their foes. Posters were and still are "designed to appeal quickly to a passing viewer and depend upon a certain instantaneous recognition" (p. 20). Although we don't know today exactly how the war posters were displayed or received, "because they cannot be studied in the surroundings in which they appeared, nor can their viewers be called to bear witness to them in any systematic way" (James, 2009, p. 16), we do know that war posters were much more widely distributed than regular advertisements. A 1915 article in The Manchester Guardian describes the poster atmosphere:

It is impossible, in London at least, to escape the war posters. They assail you from every corner. They take you in the streets and in the trains. They threaten, persuade, cajole, and frighten. Every taxicab cries out at you in forty different sharps and flats, and the only way out of the noise is inside (H. R. C., 1915 April 5, p.10).

There are "reasons to call World War I, as many have done, 'the poster war"' (James, p. 4).

Originally, we created a scaffolded plan to introduce the students to visual literacy: an in-class assignment in which groups analyze a British propaganda poster, followed later in the quarter by two worksheet assignments in which students would examine specific types of visual objects: postcards and newsstand boards. But, due to the onset of COVID-19, our institution had to transfer courses to an online environment the week before spring quarter 2020 began, and we had to adjust our plans.

We retained the scaffolded approach, but focused on enlistment and war bond posters. The arts and humanities librarian developed a video illustrating how to navigate Adam Matthew's First World War Portal for the initial worksheet. She then created a second video modelling how to interrogate a propaganda poster, and the professor created an assignment in which the students were to evaluate three posters from a pre-selected group of English-language recruitment and war bond posters from Britain, Canada, Australia, and the United States. We met after the students watched the second video, and held a Zoom group meeting prior to the assignment due date for students to start articulating what they had discovered about their selected posters. We wanted to make the students more comfortable viewing and engaging with visual materials by having them develop basic skills and to prompt the students to think critically about what they were seeing. The goals for the poster assignment, which replaced our original in-class activity plan, were to have the students: analyze the interaction of image and text from either the recruitment or war bond posters; determine the motivation for persuading the intended audience; and make arguments in a reflective essay about the posters to answer questions raised. Our discussion here will be on the second video, which modelled what students needed to do for the assignment.

In the video, we initially introduced the classic Uncle Sam propaganda poster from World War I as a point of reference, believing the students would recognize this image, and then introduced a British propaganda poster, "Red Cross or Iron Cross?" (see Figure 5), and began unpacking the image, looking closely and describing both text and image. We then determined basic background information through metadata, images, and text. After initially looking, observing, and seeing, we described what we saw in the contents of the poster: a woman, dressed in white, with a red cross symbol on her veil and around her neck, stands in the foreground, pouring a glass of water on the ground, while a soldier lying on a stretcher reaches for it. To the right, two amused men gaze upon the scene. The words Red Cross, in red, and Iron Cross, in black, scream from above the image, while the words below serve both as caption and as propaganda. We then looked at the metadata to gather basic information: it is a British propaganda poster that was intended for the home front, and which had the keywords "nurse, war wounded, anti-German propaganda, propaganda, women at war" assigned to it. Questions this poster might generate about the contents include: why is the Iron Cross being compared to the Red Cross? Perhaps the $21^{\text {st }}$-century viewer knows what the Red Cross is, but what is the Iron Cross? What do the words German sister mean and why is sister in quotation marks? Who are the two men in the background? What is the meaning of the clothes and helmets they are wearing? Are they stereotypes of Germans? Why is this poster directed at women specifically? Next, we researched definitions to contextualize the terms. The Iron Cross is a military medal that was externally perceived as a symbol of German military aggression. A sister in Britain is a nurse, not a nun, as some might have thought. The quotation marks are probably intended to be ironic or accusatory, that this nurse isn't acting like a nurse or a woman. Who are the two men? Are they Kaiser Wilhelm II and Crown Prince Wilhelm of Germany? We can look for images of military officers to try to determine their identities. The man at the rear could be the Kaiser, for he is often caricatured with the helmet, mustache, and sash. 


\section{Figure 5}

Anonymous. Red cross or iron cross? Dangerfield Printing, 1918. Source: Original Format: University of British Columbia, Library, Rare Books and Special Collections, World War I Poster and Broadside Collection (SPAM413C), doi:http://dx.doi.org/10.14288/1.0038231. Reproduced with permission from University of British Columbia Library.

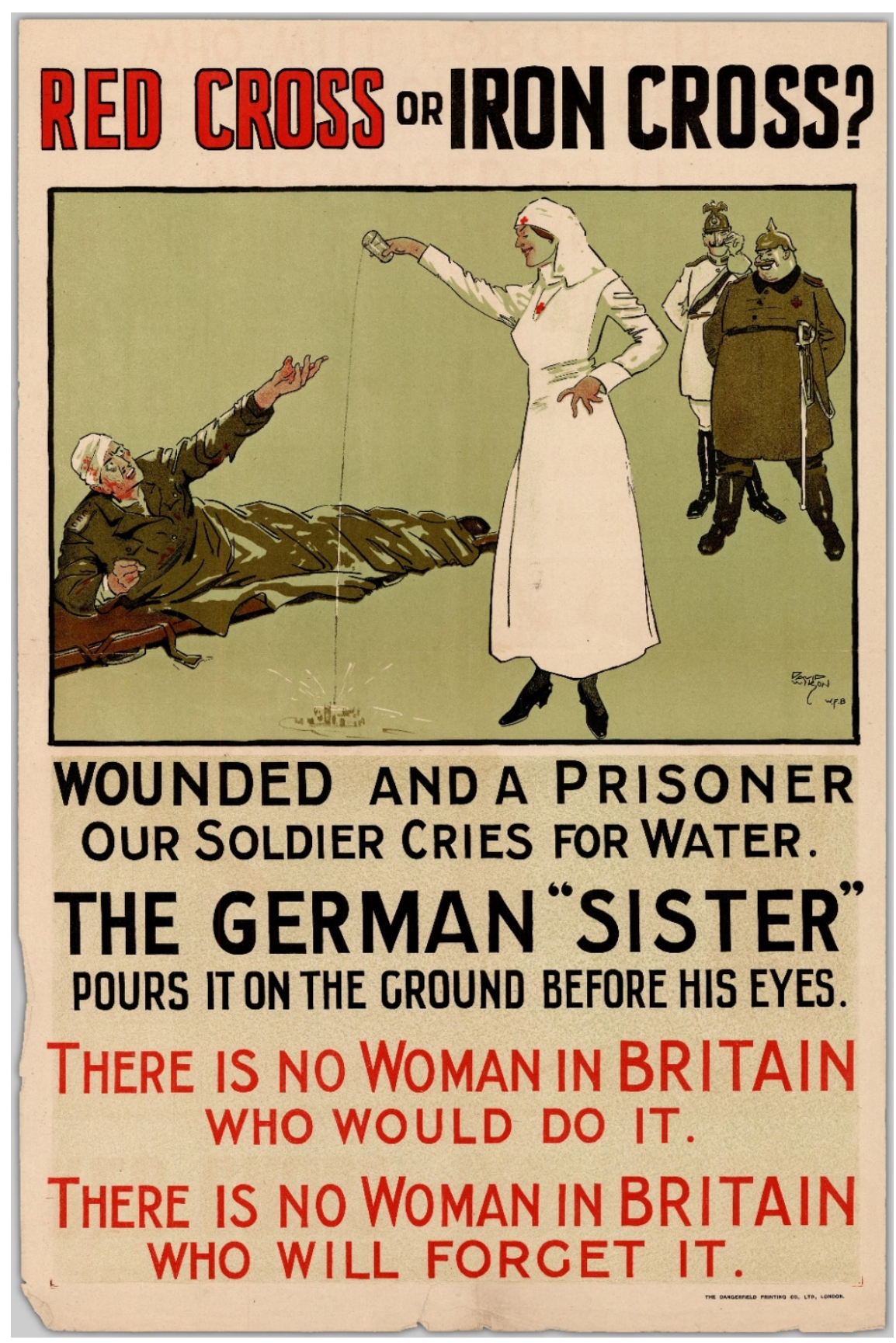

Would the audience have understood all the information being conveyed? Yes. The woman in white is a German Red Cross nurse, who is supposed to aid all soldiers, not just German soldiers, but she chooses the Iron Cross, or nationalism, over her calling. She smirks, callously pouring a glass of water on the ground. The two German soldiers, possibly someone high up in Red Cross administration as well as the Kaiser, smile approvingly at her action, giving the scene in the foreground authoritative support. The text informs 
us that the response of all British women would have been the same: disbelief and outrage that any woman would act so coldheartedly. Why is this poster directed at women, specifically? To remind British women that they have a role in the war on the home front. Possibly to build indignant morale among women, for the soldier could be their son, brother, husband, or fiancé. To portray British women as morally superior to heartless German women. To highlight the cruelty and pettiness of the German people, even their nurses. This poster could be used in projects related to women's roles in war, anti-German propaganda on the home front, stereotypes in war, and more.

We concluded the video with three other British posters that use iconographic representations of BritainBritannia, the lion, and the bulldog-to illustrate that these images, which $21^{\text {st }}$-century American students might not comprehend, were meaningful to the British at that time. We underscore that we want them to learn the visual vocabulary from the First World War to enhance their knowledge and understanding of the daily world in which soldiers and citizens existed, and not to be intimidated by using images, but to remember that images are part of the conversation - they aren't ancillary but contribute important information to the academic audience.

The poster assignment was scaffolded over the course of a week. First, we modelled techniques for students on unpacking unknown visual materials, then we discussed the range of posters as a group, and, finally, students wrote reflective papers on chosen posters. This process allowed the students enough time with the materials to thoroughly look, examine, describe, interpret, and reflect at a deeper level.

\section{Lessons Learned}

As we continue to partner with faculty on incorporating visual literacy activities into classes outside the traditional arts disciplines, we build on our previous experience with the goal of improving our knowledge and practices. There are important lessons to be learned with each class, both in terms of successes, or what worked well, as well as with challenges. And like all instruction interactions, we recognize that learning is collaborative and shared among students, faculty, and librarians. We've found the following to be helpful guidelines.

It's important to recognize that librarians and faculty have different experiences and, correspondingly, varying levels of comfort with conducting visual analysis. Of the three librarians, the arts and humanities librarian has the most extensive knowledge about working with visual material. But as we've learned, visual analysis lends itself to many different disciplinary perspectives. In fact, visual analysis is a standard part of research methodology in non-arts fields, including anthropology, communication, history, and sociology, if employed to different degrees at the undergraduate and graduate levels, but it is uncertain how frequently visual analysis is actively taught. Consequently, don't let your inexperience or discomfort inhibit incorporating visual analysis activities into library instruction. We live in a heavily visual world, images are ubiquitous, and everyone (librarians, faculty, and students alike) will benefit from learning how to think critically and purposefully about images. Building upon previous experience to strengthen and expand your visual literacy skills will be an ongoing process, but we advise "jumping in," rather than waiting for the time when you feel you've become an expert. Instead, embrace the adage "learn by doing," for yourself as well as for your students.

To ensure that the visual analysis activities will be integral to the course and enhance the students' learning experience, work closely with the faculty member to plan activities that support the course learning outcomes or goals. Since non-arts courses may not have explicit visual learning outcomes, consider this an opportunity to be creative. As part of this effort, make use of the visual materials available in your library's archives and special collections, or/and your digital collections. In addition to the collections discussed in this essay, for example, we've used photographs from our university's student newspaper, The Clarion, to examine issues of gender, race, and representation on campus over time. Moreover, especially when working with visual material from the past, it will be crucial to support students' learning with scaffolded instruction that introduces them not only to visual analysis concepts and techniques, but which also provides historical and cultural contexts.

Finally, we recommend that you consider carefully if there are any ethical issues in using the images 
selected. Both analog and digital special collections, in particular those concerning vulnerable or racialized groups, may have been acquired originally at a time when the rights of these people were not considered or permission secured. This is especially important to take into account if you are not a member of those communities. As discussed above, this remains a subject of ongoing deliberation for us about how or whether to use the Curtis prints in our teaching. We also encourage you to think creatively about how visual analysis activities might be adapted for students who are visually impaired. And, as is central to all teaching, it is important to assess what has worked well with the visual analysis activities, to note what can be improved, and to remain flexible so that you can make changes for the next time.

Our experience using visual material to teach students from non-arts disciplines about the past has been extremely rewarding. We've found that students often engage more fully with visual material in ways not presented by studying texts alone. Images, in particular, seem to speak to students and enable them to connect with and learn about the experiences of people from different cultures and time periods, as long as they are provided with the skills, support, and historical and cultural contexts to guide their analysis. Given this foundation, students can gain a richer understanding of the interconnections between the past and present, and apply these skills beyond the classroom and throughout their lives.

\section{References}

ACRL. (2016). Framework for information literacy for higher education. http://www.ala.org/acrl/standards/ilframework

ACRL. (2011). ACRL visual literacy competency standards for higher education. http://www.ala.org/acrl/standards/visualliteracy

Beatty, N. A. (2013). Cognitive visual literacy: From theories and competencies to pedagogy. Art Documentation: Journal of the Art Libraries Society of North America, 32(1), 33-42. https://doi.org/10.1086/669987

Beatty, N. A., \& Hernandez, E., Jr. (2019). Socially responsible pedagogy: Critical information literacy and art. Reference Services Review, 47(3), 280-293. doi:10.1108/RSR-02-2019-0012

Brown, N. E., Bussert, K., Hattwig, D., \& Medaille, A. (2016). Visual literacy for libraries: A practical, standards-based guide. ALA Editions.

Chassanoff, A. M. (2018). Historians' experiences using digitized archival photographs as evidence. The American Archivist, 81(1), 135-164.

Clemmer-Smith, R., Gilbert, A., Halaas, D. F., Stratton, B. J., Tinker, G. E., \& Wadsworth, N.D. (November 2014). Report of the John Evans study committee. University of Denver.

Grimm, S., \& Meeks, A. (2017). Break the stereotype! Critical visual literacy in art and design librarianship. Art Documentation: Journal of the Art Libraries Society of North America, 36(2), 173-190. https://doi.org/10.1086/694238

H. R. C. (1915, April 5). The appeal of the poster. The Manchester Guardian, p. 10.

Harris, V., \& Hepburn, P. (2013). Trends in image use by historians and the implications for librarians and archivists. College \& Research Libraries, 74(3), 272-287. https://doi.org/10.5860/crl-345

Henzi, S. (2016). 'A necessary antidote': Graphic novels, comics, and Indigenous writings. Canadian Review of Comparative Literature, 43(1), 23-38. doi:10.1353/crc.2016.0005

James, P. (2009). Introduction. In P. James (Ed.), Picture this: World War I posters and visual culture (pp. 1-36). University of Nebraska Press. 
Johnson, K. (2016) Captivity narratives. In American Literature, Oxford University Press. doi:10.1093/OBO/9780199827251-0115

Keeran, P., Bowers, J., Crowe, K., and Korfitzen, K. (2019). Using visual materials to teach information literacy outside the arts curriculum. Art Documentation: Journal of the Art Libraries Society of North America, 38(1), 141-158. https://doi.org/10.1086/702894

Lutz, C., \& Collins, J. The photograph as an intersection of gazes: The example of National Geographic. (1991). Visual Anthropology Review, 7(1), 134-149. doi:10.1525/var.1991.7.1.134

Makepeace, A. (Writer, Director, \& Producer). (2000). Coming to light: Edward S. Curtis and the North American Indians [TV]. Makepeace Productions, Inc.; Thirteen/WNET; Bullfrog Films.

Matusiak, K. K., Heinbach, C., Harper, A., \& Bovee, M. (2019). Visual literacy in practice: Use of images in students' academic work. College \& Research Libraries, 80(1), 123-139. https://doi.org/10.5860/crl.80.1.123

Meeks, A. (2017). Learning to look critically: Teaching and learning visual literacy in art and design librarianship. Art Libraries Journal, 42(2): 89-94. https://doi.org/10.1017/alj.2017.9

NAGPRA Comics website. (2019). https://nagpracomics.weebly.com/

Schwartz, J. (2018). Visual literacy: Academic libraries address 21st century challenges. Reference Services Review, 46(4), 479-499. https://doi.org/10.1108/RSR-04-2018-0048

Sinclair, N. J. (2020, January 30). History. Mazinbiige Indigenous Graphic Novel Collection. https://libguides.lib.umanitoba.ca/c.php?g=651900\&p=4572449

Stratton, B. J. (2013). Buried in shades of night: Contested voices, Indian captivity, and the legacy of King Philip's War. University of Arizona Press.

Thompson, D., Wegmann, M., \& Greer, K. (2020, Sept. 25) Visual literacy in the 21st century: Challenges and opportunities identified through empirical study [Panel presentation]. International Visual Literacy Association 2020 Conference, https://ivlaconference.org/

Toledo Museum of Art. Visual literacy: The art of seeing. https://www.toledomuseum.org/education/visualliteracy/art-seeing-art

APA citation format $\left(7^{\text {th }}\right.$ edition) for this publication:

Keeran, P., Crowe, K,. \& Jennifer B., J (2021). Visual encounters with the past: Teaching visual literacy to enhance historical and cultural understanding. In J. Lee, S. M. Christensen, S. Beene, $X$. Chen, and W. Huang (Eds.), Visual literacy in the virtual realm: The book of selected readings 2021 (pp. 53-67). International Visual Literacy Association.

https://doi.org/10.52917/ivlatbsr.2021.016 